\title{
A Chemotaxonomic Approach to the Fatty Acid Content of Some Acacia Taxa from Central Sudan
}

\author{
Eiman Mohammed Ali Mustafa, Hatil Hashim El-Kamali* \\ Department of Botany, Faculty of Science and Technology, Omdurman Islamic University, Omdurman, Sudan \\ Email: "hatilhashim@gmail.com
}

Received 3 January 2016; accepted 19 January 2016; published 22 January 2016

Copyright (C) 2016 by authors and OALib.

This work is licensed under the Creative Commons Attribution International License (CC BY).

http://creativecommons.org/licenses/by/4.0/

(c) $\underset{\mathrm{EY}}{\mathrm{B}}$ Open Access

\section{Abstract}

The aim of the present study was to evaluate the composition of fatty acids of mature seeds of some Acacia taxa (Acacia mellifera, A. nilotica ssp. adansonia, A. nilotica ssp. nilotica, $A$. oerfota, $A$. polycantha ssp. campylacantha, $A$. enegal var. senegal, $A$. seyal var. seyal and $A$. sieberiana var. sieberiana) from Central Sudan in order to reveal their potential classification to be used as taxonomic markers. Results showed that Acacia seed oils were mainly unsaturated fatty acids ranging in content between $51.20 \%$ to $86.90 \%$, whereas, saturated fatty acids ranged between $12.49 \%$ to $48.80 \%$. Oleic acid was the major fatty acid $24.24 \%-80.19 \%$, followed by linoleic $(5.70 \%$ $58.73 \%$ ). Palmiticacid was the dominant saturated fatty acid $12.39 \%-19.2 \%$, followed by stearic acid $0.0 \%-34.52 \%$. The results showed some relationships between the Acacia taxa with respect to fatty acid contents. Acacia seed oils showed a remarkable uniformity in terms of their higher content of oleic acid and linoleic acid. It is proposed that this can be of chemo-taxonomical interest and their quantities may indicate closer or more distant relationships between the considered taxa. The highest degree of pairing affinity was observed between $A$. oerfota and $A$. mellifera (92.58\%), followed by $A$. oerfota and $A$. sieberiana $(89.93 \%)$ and between $A$. niloticas sp. adansonia and $A$. sieberiana $(\mathbf{8 8 . 5 4 \%})$. Hence it is suggested that $A$. mellifera and $A$. sieberiana are the most closely related, as also $A$. oerfota and $A$. senegal.

\section{Keywords}

Fatty Acid Profile, Acacia Taxa, Taxonomic Marker, Pairing Affinity, Seeds, Sudan

Subject Areas: Plant Science

\section{Introduction}

Seed oils of plants of Leguminosae have been investigated and it has attracted interests of researchers [1]-[7].

"Corresponding author. 
But, very scant information is available on the fatty acid composition of Acacia genus, particularly in Sudan. Variation in oil content and fatty acid composition of the seed oil of Acacia species collected from the northwest zone of India were observed by Khan et al., 2012 [8]. Content and composition of fatty acids of seed lipids can serve as taxonomic markers in higher plants [9]-[12].

Seed oils with a substantial amount of very long chain of fatty acids have attracted attention because of their value for industrial purposes. Furthermore, these compounds can be of chemotaxonomic significance [13].

The aim of this study is to identify and differentiate some Acacia taxa with respect to fatty acid content. In order to achieve this goal, the following objectives were set 1) Quantitative determination of fatty acids from seed oil by Gas Chromatography; 2) Evaluation of pairing affinity (or similarity Index) between eight interrelated taxa of studies Acacia based on fatty acid composition of seeds as taxonomic markers.

\section{Materials and Methods}

\subsection{Materials}

Acacia under study (8 taxa): Acacia mellifera, A. niloticas sp. adansonia, A. nilotica ssp. nilotica, A. oerfota, A. polycantha ssp. campylacantha, A. senegal var. senegal, A. seyal var. seyal and $A$. sieberiana var. sieberiana.

The voucher specimens were kept at Herbarium of Botany Department, Faculty of Science and Technology, Omdurman Islamic University. The identification of the studied taxa was done according to AL-Amin, 1990 [14].

\subsection{Seeds Collection}

The taxa under investigation were brought from Soba Research Centre, Khartoum. Seeds were collected from various areas of West Sudan. These seeds were identified by the plant taxonomist of Soba Research Forests, Ustaz Hassan Al-Bager, Ministry of Science and Technology, Khartoum.

\subsection{Fatty Acids Content}

\subsubsection{Preparation of Methyl Ester for Gas Chromatography}

Seed oils were extracted from Acacia taxa studied according to Official Method of Analysis (AOAC) (1984) [15]. Fatty acids were determined according to Christie (1990) [16]. The samples were prepared by dissolving 1 $\mathrm{ml}$ of oil from each sample in eight round-bottomed flasks (100 ml) in $6 \mathrm{ml}$ of $0.5 \mathrm{M} \mathrm{NaOH}$ (Methanolic) and shaken well. Then, $6 \mathrm{ml}$ of $1 \%$ methanolic $\mathrm{H}_{2} \mathrm{SO} 4$ was added and shaken well, after that the mixture left overnight at $50^{\circ} \mathrm{C}$. Two ml. n-hexane were added and shaked. Enough saturated sodium chloride was added to level of the neck flask. $1 \mathrm{ml}$ of the upper layer was taken into a glass stoppered tube. Then, anhydrous Sodium sulphate were added to $1 \mathrm{ml} \mathrm{n}$-hexane to remove the moisture. The top n-hexane phase was transferred into a vial and injected into Gas Chromatograph equipped with the capillary column.

\subsubsection{Conditions for GC}

Ashimadz (GC-2010) Gas chromatograph apparatus (Japan).

\begin{tabular}{cc}
\hline Sample volume (inj) & $0.5 \mathrm{ml}$ \\
Column & PEGA $10 \%$. \\
Column temp & $240^{\circ} \mathrm{C}$. \\
Injection & $280^{\circ} \mathrm{C}$. \\
Detection & $220^{\circ} \mathrm{C}$. \\
Carrier gas & Nitrogen \\
Flow rate & $1.5 \mathrm{ml} / \mathrm{min}$. \\
Attenuation & $16 \times 10$. \\
Detector & FID (flame ionization detector). \\
Chart speed & $1 \mathrm{u} \mathrm{n} / \mathrm{mw}$ \\
\hline
\end{tabular}




\subsection{Pairing Affinity (PA) Values between Studied Taxa of Acacia Seeds Based on Distribution of Fatty Acids}

The method of Pairing Affinity (or similarity Index) described by Sokal and Sneath (1963) [17] was used to analyze the data of fatty acid composition and determine the Pairing Affinity (PA) between the two taxa of Acacia species. The degree of Pairing Affinity between the two taxa was calculated according to the following formula:

Pairing Affinity (PA) = Fatty acids common to A to B/Total Fatty acids in A and B $\times 100$

\section{Results and Discussion}

Fatty acids profile for n-hexane extract of seed oil from selected eight Acacia taxa (Acacia mellifera, A. niloticas sp., Adansonia, A. nilotica ssp. nilotica, A. oerfota, A. polycantha ssp. campylacantha, A. Senegal var. senegal, A. seyal var. seyal and A. sieberiana var. sieberiana) were determined by using GC.

The fatty acids methyl ester composition of the studied taxa are shown in Table 1 . The following fatty acids were identified: palmitic, stearic, oleic, linoleic and arachidonic acids. Six fatty acids detected were identified in A. polyacantha, five fatty acids were identified in A. mellifera, A. oerfota, A. senegal and A. seyal, four acids detected were identified in A. nilotica ssp. nilotica and three fatty acids detected were identified in A. nilotica ssp. adansonia and A. sieberiana var. sieberiana.

Table 2 shows that the total saturated fatty acids of eight Acacia taxa studied ranged between $12.4 \%$ to 48.80\%. Lowest value noticed in Acacia oerfota, whereas the highest value obtained by Acacia sieberiana. Stearic acid in seed oil of $A$. sieberiana was the predominantly saturated fatty acids. On the other hand, the total of unsaturated fatty acids ranged between $51.20 \%$ to $86.90 \%$. A sieberiana got the lowest value, and the highest value gained by Acacia oerfota (81.19\%). Oleic acid in seed oils of A. mellifera (63.45\%) and A. senegal $(60.80 \%)$ were the predominantly unsaturated fatty acids.

The chemotaxonomic importance and potential of fatty acids in this genus was confirmed by this study. Differences in fatty acid patterns illustrate some chemotaxonomic relationships between the genera members studied. Since the fatty acid patterns of Acacia taxa seed oils showed a remarkable uniformity in terms of their content, oleic-linoleic acid pattern, oleic-palmitic pattern and linoleic-stearic pattern. It is proposed that this can be of chemotaxonomical interest and their quantity may indicate closer or more distant relationships between the considered members of the genus. Our results on Acacia taxa, seed fatty acids are in good agreement with report of Bagci and Sahin, 2004 [18].

Acacia taxa can be classified according to unsaturated: saturated ratio as the following patterns: 1:1 pattern: $A$. sieberiana; 3:1 A. seyal; 4:1 A. nilotica, A. polycantha, A. Senegal; 5:1 A. mellifera and 7:1 A. oerfota.

Table 1. Fatty acids methyl ester composition of eight Acacia taxa.

\begin{tabular}{|c|c|c|c|c|c|c|}
\hline Acacia taxa & $\begin{array}{l}\text { Palmiticacid } \\
\text { C16:0 }\end{array}$ & $\begin{array}{l}\text { Stearic acid } \\
\text { C18:0 }\end{array}$ & $\begin{array}{l}\text { Oleic acid } \\
\text { C18:1 }\end{array}$ & $\begin{array}{c}\text { Linoleic } \\
\text { acid } \\
\text { C18:2 }\end{array}$ & $\begin{array}{l}\text { Arachidonicacid } \\
\text { C20:0 }\end{array}$ & Unidentified \\
\hline Acacia mellifera & 13.3630 & - & 63.4540 & 6.3620 & 1.513 & 15.3080 \\
\hline $\begin{array}{c}\text { Acacia nilotica ssp. } \\
\text { Adansonia }\end{array}$ & 17.0127 & - & 24.2481 & 58.7392 & - & - \\
\hline $\begin{array}{c}\text { Acacia nilotica ssp. } \\
\text { Nilotica }\end{array}$ & 15.4188 & 5.1125 & 26.9570 & 52.5117 & - & - \\
\hline Acacia oerfota & 12.3940 & - & 80.1910 & 5.7040 & 1.0510 & 0.6610 \\
\hline $\begin{array}{l}\text { Acacia polyacantha } \\
\text { ssp. Campylacantha }\end{array}$ & 14.1225 & 5.3630 & 37.8340 & 37.3476 & 5.0004 & 0.3326 \\
\hline Acacia enegal & 19.2000 & - & 60.8000 & 14.9000 & 5.1000 & 0.0720 \\
\hline Acacia seyalvar. seyal & 15.2173 & 8.6405 & 32.0828 & 40.0736 & 3.9858 & - \\
\hline $\begin{array}{c}\text { Acacia sieberiana var. } \\
\text { sieberiana }\end{array}$ & 14.2590 & 34.5233 & - & 51.2176 & - & - \\
\hline
\end{tabular}

C: No of carbon atoms in fatty acids. 
Fatty acids in Acacia taxa can also be classified according to some relationships as follows:

1) Linoleic-oleic type fatty acid pattern in A. nilotica ssp. adansonia (2:1), A. nilotica ssp. Nilotica (2:1), A. seyal var. seyal (1:1) and A. polyacantha ssp. campylacantha, (1:1).

2) Oleic-palmitic type:

A. mellifera (5:1), A. oerfota (6:1), A. senegal (3:1).

3) Linoleic-Stearic type: A. sieberiana var. sieberiana (1.5:1).

Since the fatty acids patterns of Acacia seed oils showed a remarkable uniformity in terms of their higher content of the oleic (except A. sieberiana) and Linoleic acids. It is proposed that this can be of chemotaxonomical interest and their quantity may indicate closer more distant relationships between the considered taxa of genus.

The results of pairing affinity between the eight taxa based on the results of free fatty acid analyses have been summarized in Table 3. Cluster pairing affinity (or similarity index) between eight interrelated studied taxa of Acacia genus was evaluated on the basis of fatty acid composition (Table 1) of seeds as taxonomic markers to assess the phylogenic interrelationships and plant affinity. Considerable amount of homology was observed in sub-species belonging to the same species.

The highest degree of pairing affinity between A. oerfota and A. mellifera (92.58\%), followed by A. oerfota and A. sieberiana (89.93\%), and between A. nilotica ssp. adansonia and A. sieberiana (88.54\%). Hence A. mellifera and $A$. sieberiana are the most closely related, as also $A$. oerfota and A. senegal.

Table 2. Contents of total saturated and unsaturated fatty acids.

\begin{tabular}{ccc}
\hline Acacia taxa & Total Saturated Fatty Acids & Total Unsaturated Fatty Acids \\
\hline Acacia mellifera & 13.4 & 71.3 \\
Acacia nilotica ssp. Adansonia & 17 & 83.0 \\
Acacia nilotica ssp. Nilotica & 20.5 & 79.5 \\
Acacia oerfota & 12.4 & 86.9 \\
Acacia polyacantha ssp. campylacantha & 19.5 & 80.2 \\
Acacia Senegal & 19.2 & 80.8 \\
Acacia seyal var. seyal & 23.9 & 72.2 \\
Acacia sieberiana var. sieberiana & 48.8 & 51.2 \\
\hline
\end{tabular}

Table 3. Results of pairing affinity between the eight taxa based on of fatty acids content.

\begin{tabular}{|c|c|c|c|c|c|c|c|c|}
\hline & $\begin{array}{c}\text { A. } \\
\text { nilotica ssp. } \\
\text { nilotica }\end{array}$ & $\begin{array}{c}\text { A. } \\
\text { sieberiana var } \\
\text { sieberiana }\end{array}$ & $\begin{array}{c}\text { A. } \\
\text { mellifera }\end{array}$ & $\begin{array}{l}\text { A. polyacantha } \\
\text { spp. } \\
\text { camplyacantha }\end{array}$ & $\begin{array}{l}\text { A. senegal } \\
\text { var senegal }\end{array}$ & $\begin{array}{l}\text { A. seyal } \\
\text { var. seyal }\end{array}$ & A. oerfota & $\begin{array}{l}\text { A. nilotica ssp. } \\
\text { Adansonia }\end{array}$ \\
\hline $\begin{array}{l}\text { A. nilotica ssp. } \\
\text { nilotica }\end{array}$ & 100 & 82.61 & 84.62 & 77.45 & 79.76 & 75.81 & 86.77 & 81.23 \\
\hline $\begin{array}{l}\text { A. sieberiana var. } \\
\text { sieberiana }\end{array}$ & & 100 & 88.02 & 80.60 & 82.90 & 78.95 & 89.93 & 84.36 \\
\hline A. mellifera & & & 100 & 82.45 & 84.94 & 80.66 & 92.58 & 86.52 \\
\hline $\begin{array}{l}\text { A. polyacantha } \\
\text { spp. } \\
\text { camplyacantha }\end{array}$ & & & & 100 & 77.75 & 73.79 & 84.75 & 79.16 \\
\hline $\begin{array}{c}\text { A. Senegal var. } \\
\text { senegal }\end{array}$ & & & & & 100 & 76.11 & 87.69 & 81.52 \\
\hline $\begin{array}{l}\text { A. seyal var. } \\
\text { seyal }\end{array}$ & & & & & & 100 & 83.08 & 77.57 \\
\hline A. oerfota & & & & & & & 100 & 88.54 \\
\hline $\begin{array}{l}\text { A. nilotica ssp. } \\
\text { adansonia }\end{array}$ & & & & & & & & 100 \\
\hline
\end{tabular}


The high oleic fatty acid was extracted from Acacia oerfota seed oil (80.19\%), A. mellifera (63.45\%) and in A. Senegal var. senegal strongly indicates its prospects for commercial extraction.

A number of studies suggest that the unsaturated fatty acid component of Leguminosae seed oils resemble each other and oleic and linoleic acids were the main components in seed oil.

\section{Conclusion}

Acacia species are the potential renewable natural resources in Africa, including Sudan. The identification of the fatty acids will be of great help to understand the importance of the seeds of these species to humanity and the chemotaxonomic affinity of the studied taxa. It was concluded from this study that Acacia taxa could be classified according to their fatty acid composition to unsaturated and saturated ratio or might be classified according to fatty acid pattern (linoleic acid-oleic acid type, oleic-palmitic type and linoleic-stearic type). The highest degree of pairing affinity was between Acacia oerfota and A. mellifera (92.58\%) and between A. oerfota and A. sieberiana (89.93\%). The patterns of distribution of genetic diversity among populations of these taxa should be examined for future breeding programmes.

\section{References}

[1] Chowdury, A.R., Banerjii, R., Misra, G. and Nigam, S.K. (1984) Studies on Leguminous Seeds. Journal of the American Oil Chemists' Society, 61, 1023-1024. http://dx.doi.org/10.1007/BF02636208

[2] Kleiman, R. (1988) Genetic Diversity of Plant Lipids in Plant Germplasm. In: Apple White, T.H., Ed., Proceeding of the World Conference on Biotechnology for the Fats and Oils Industry, 73-77.

[3] Ferlay, V., Malet, G., Masson, A. and Ucciani, E. (1993) Fatty Acid Composition of Seed Oils from Sapontaneous Species of the Meditrranean. In AGRIS. Fr Language, 48. http://aims.fao.org/serial/c-9833af9d

[4] Ucciani, E., Malet, G., Gamisans, J. and Gruber, M. (1994) Fatty Acid Composition Seed Oils Meditrranean Herbaceous Species. Grasas Y Aceitas-Sevilla, 45, 107.

[5] Chowdury, A.R. and Banerjii, R. (1995) Studies on Leguminosae Seeds. Fett Wissenschafttechnologie-Fat Science Technology, 97, 457-458.

[6] Muraliharudu, Y. and Nagaraj, G. (1995) Seed Characteristics and Fatty Acids Composition of Linseed Cultivars. Journal of the Oil Technologists' Association of India, 27, 11-16.

[7] Bağci, E. and Vural, M. (2001) Fatty Acid Composition of Astragalus pycnocephalus var pycnocephalus and Astragalus condensatus, A Chemotaxonomic Approach. Journal of the Institute of Science and Technology of Gazi University, 14, 1305-1311.

[8] Khan, R., Srivastava, R., Khan, M.A., Alam, P., Zainul Abdinc, M. and Mahmooduzzafar (2012) Variation in Oil Content and Fatty Acid Composition of the Seed Oil of Acacia Species Collected from the Northwest Zone of India. Journal of the Science of Food and Agriculture, 92, 2310-2315. http://dx.doi.org/10.1002/jsfa.5627

[9] Harborne, J.B. and Turner, B.I. (1984) Plant Chemosystematics. Academic Press, London, 180-191.

[10] Hegnauer, R. (1989) Chemotaxonomie der Pflancen. Lehrbücher und Monographien aus dem Gebiete der Exakten Wissenschaften, 8, 611-612. http://dx.doi.org/10.1007/978-3-0348-9283-4

[11] Aitzetmuller, K. (1993) Capillary GLC Fatty Acid Fingerprints of Seed Lipids-A Tool in Plant Chemotaxonomy. Journal of High Resolution Chromatography, 16, 488-490. http://dx.doi.org/10.1002/jhrc.1240160809

[12] Aitzetmuller, K. and Tsevegsuren, N. (1994) Seed Fatty Acid, "Front-End” Desaturases and Chemotaxonomy-Case Study in the Ranunculaceae. Journal of Plant Physiology, 143, 538-543. http://dx.doi.org/10.1016/S0176-1617(11)81820-1

[13] Spitzer, V., Marx, F., Maia, J.G.S. and Pfeilsticker, K. (1990) Curupiratefeensis (Olacaceae)—A Rich Source of Long Chain Fatty Acids. Fat.Sci. Technol., 92, 165.

[14] Al-Amin, H.A. (1990) Trees and Shrubs of the Sudan. Ithaca Press, 484 p.

[15] AOAC (1984) Official Method of Analysis. 14th Edition, Association of Official Analytical Chemists, Washington DC.

[16] Christie, W.W. (1990) Preparation of Methyl Esters Part-1. Lipid Technology, 2, 48-49.

[17] Sokal and Sneath (1963) Principles of Numerical Taxonomy. W.H. Freeman, San Francisco.

[18] Bagci, E. and Sahin, A. (2004) Fatty Acid Patterns of the Seed Oils of Some Lathyrus Species L. (Papilionideae) from Turkey, A Chemotaxonomic Approach. Pakistan Journal of Botany, 36, 403-413. 